\title{
Liver Damage Induced by Succinylacetone: A Shared Redox Imbalance Mechanism between Tyrosinemia and Hepatic Porphyrias
}

\author{
Vanessa E. S. Cardoso, ${ }^{a}$ Fernando Dutra,${ }^{b}$ Chrislaine O. Soares, ${ }^{a}$ \\ Atecla N. L. Alves, ${ }^{c}$ Estela Bevilacqua, ${ }^{d}$ Sonia M. Gagioti, ${ }^{d}$ Carlos A. A. Penatti ${ }^{e}$ and \\ Etelvino J. H. Bechara*,f
}

${ }^{a}$ Departamento de Bioquímica, Instituto de Química, Universidade de São Paulo, 05508-900 São Paulo-SP, Brazil

${ }^{b}$ Centro de Ciências Biológicas e da Saúde, Universidade do Cruzeiro do Sul, 08060-070 São Paulo-SP, Brazil

${ }^{c}$ Laboratório Central do Hospital das Clínicas, Faculdade de Medicina, Universidade de São Paulo, 01246-903 São Paulo-SP, Brazil

${ }^{d}$ Departamento de Biologia Celular e Desenvolvimento, Instituto de Ciências Biológicas, Universidade de São Paulo, 05508-900 São Paulo-SP, Brazil

${ }^{e}$ Departamento de Ciências Médicas, Universidade Nove de Julho, 01504-001 São Paulo-SP, Brazil

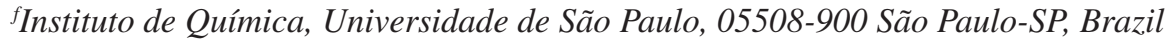

\begin{abstract}
To show liver failure mediated by 5-aminolevulinic acid (ALA), a heme precursor accumulated in inborn and acquired porphyrias, rats were treated with succinylacetone methyl ester (SAME). Treated rats underwent the expected ALA accumulation in plasma, liver and urine as a result from inhibition of ALA dehydratase (ALAD) activity. The enzyme activity decreased concomitantly with diminished urinary coproporphyrin levels. Additionally, liver protein carbonyls, iron and ferritin were higher in groups treated with a lower concentration of SAME whereas malondialdehyde was higher in the group treated with a higher ester dose. Consistent with these biochemical data, chronic treatment SAME was associated with induced oxidative subcellular and tissue damage revealed by cytosolic and mitochondrial changes within the liver cells. Altogether, these data expand the understanding of the direct biochemical mechanism for liver cell death in hepatic inborn disorders by generating excess ALA and may foster future therapeutic-driven strategies to preserve liver function.
\end{abstract}

Keywords: 5-aminolevulinic acid, succinylacetone, intermittent acute porphyria, hereditary tyrosinemia type 1 , redox imbalance

\section{Introduction}

Succinylacetone (SA) is a tyrosine metabolite that accumulates in tyrosinemia type 1 (HT1) carriers. ${ }^{1,2}$ SA inhibits ALA-dehydratase (ALA-D) and promotes 5-aminolevulinic acid (ALA) accumulation, ${ }^{3}$ which is presumed to cause renal dysfunction, liver cirrhosis and cancer, and neuropsychiatric manifestations in HT1 affected individuals. ${ }^{2,4}$ In animal models, chronic exposure to SA leads to ALA-D inhibition, especially in liver, kidneys and brain that seem to preferentially accumulate and retain SA from extracellular and circulating fluids. ${ }^{5}$

*e-mail: ejhbechara@gmail.com
Preliminary experiments confirmed a 'hyperoxidative' status that was suggested by outmatched putative chemical and enzymatic biomarkers of redox imbalance. ${ }^{6,7}$ However, iron accumulation and oxidative stress in the liver have also been involved in the pathophysiology of SA-induced liver toxicity and this redox imbalance may be directly related to ALA overload as the oxidative pivot therein.

ALA levels typically peaks in the plasma and urine during acute porphyric and tyrosinemic clinical episodes. ${ }^{1,8-10}$ Excess ALA has been shown in vivo and in vitro to cause oxidative injury to biomolecules such as proteins, DNA modification and fragmentation, and structural disruption of lipid bilayers and of cell organelles such as mitochondria and synaptosomes. ${ }^{6}$ Thus, it is 
tempting to correlate the mitochondrial and DNA oxidation found in the liver of ALA-treated rats to the well-known high incidence of liver failure and hepatocarcinoma in acute intermittent porphyria (AIP) and HT1 patients who have chronically been exposed to 10 to 100 times elevated ALA hepatic levels. ${ }^{4-6}$ Accordingly, recent studies on xenobiotics and liver-metabolized dietary supplements advocate the link between redox imbalance and impaired liver cell function in an array of human disorders. ${ }^{8,11}$

Increased ALA intake in experimental models of AIP and HT1 offers competing interpretations on liver damage: porphyrin-linked photodynamic action within the hepatocyte milieu through singlet-oxygen generation ${ }^{12}$ opposed by ALA-driven oxidative effects mediated by free radicals. ${ }^{6,13,14}$ However, regarding the evidence that SA-promoted inhibition on ALA-D prevents porphyrin synthesis, it favors the latter interpretation on liver damage caused by the direct ALA accumulation in these heme deficiency disorders. In order to advance in experimentally assessing liver heme disorders, we studied the effects of the ALA-D inhibition by SA methyl ester (SAME) on heme metabolite biochemistry and hepatic cell viability and structure. We show here that overproduction of ALA in SAME-treated rats can well mimic the liver mitochondrial damage long detected in liver biopsies of porphyric individuals by Biempica et al. ${ }^{15}$ attributed herein to impairment of the animal redox balance.

Our working hypothesis to connect the observed biochemical and cellular alterations with SAME-induced ALA accumulation and resulting redox imbalance is illustrated by the Scheme 1 .

\section{Experimental}

SAME was prepared by methylation of calculated amounts of SA (Sigma Chemcial Co. (St. Louis, MO, USA)) dissolved in ethyl ether with Diazald $^{\circledR}$, as described by Rocha et al. ${ }^{7}$

\section{Animal care and treatments}

All the experiments were approved by the local Ethics and Animal Care Committee (Protocol CECUA 20-03-2007), which follows the American NIH guidelines for animal care and use. Male Wistar rats (250-300 g), bred and lodged in the Institute of Chemistry animal facility, at University of São Paulo, were housed in metabolic cages under controlled temperature $\left(22^{\circ} \mathrm{C}\right)$, humidity and light $(12 \mathrm{~h}$ light-dark cycles). The animals were fasted for $44 \mathrm{~h}$ during i.p. treatment with three doses of SAME or saline at 6, 24 and $42 \mathrm{~h}$, and were sacrificed $2 \mathrm{~h}$ after the last injection. Water was provided ad libitum. The animals were divided randomly into 4 groups. The control group (I) was treated with saline $\left(0.67 \mathrm{~mL} \mathrm{~kg}^{-1}\right.$ body weight, $\left.\mathrm{pH} 7.2\right)$, while groups II to IV were treated, respectively, with 10, 40 and $80 \mathrm{mg}$ SAME $\mathrm{kg}^{-1}$ body weight, $\mathrm{pH}$ 7.2. Blood and liver samples were collected and stored at $-80^{\circ} \mathrm{C}$ until analysis. Urine was collected for $6 \mathrm{~h}$ prior to the first SAME injection and during the $18 \mathrm{~h}$ intervals between injections.

\section{Metabolite and enzyme analyses}

ALA pre-derivatized with acetylacetone and formaldehyde was determined in liver, plasma and urine samples using a high-performance liquid chromatography (HPLC) system with fluorescent detection as described by Murata et al. ${ }^{16}$ whereas liver ALA-D activities in liver extracts were estimated spectrophotometrically according to Sassa. ${ }^{17}$ Urinary coproporphyrin (COPRO) was evaluated on an HPLC system with fluorescent detection by the method reported by Cypriani et al. ${ }^{18}$

All putative indices of oxidative stress in tissue samples were determined by procedures widely reported in the literature. As a marker of lipid peroxidation, malondialdehyde (MDA) was measured in liver samples by HPLC according to Estebauer et al., ${ }^{19}$ and liver protein carbonyl levels were determined as described by

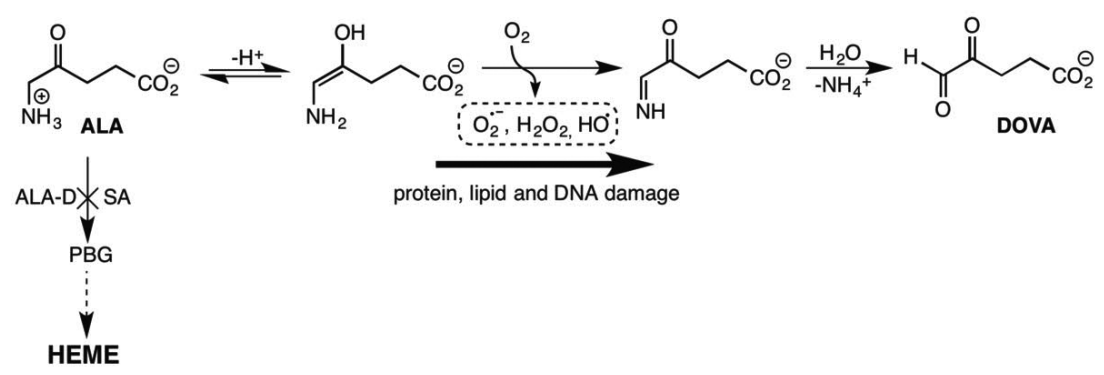

Scheme 1. Envisaged mechanism of ALA-driven redox imbalance in SAME-treated rats. ${ }^{6}$ SA strongly inhibits $\left(\mathrm{K}_{\mathrm{i}}=30\right.$ nM) ALA-dehydration to porphobilinogen (PBG) in the heme biosynthetic pathway leading to ALA accumulation in the rat liver and other organs. Excess ALA undergoes enolization and further metal-catalyzed oxidation by molecular oxygen yielding ammonium ion and 4,5-dioxovaleric acid (DOVA), a multistep reaction mediated by superoxide, hydrogen peroxide and hydroxyl radical. These reactive oxygen species may reportedly cause oxidative damage to protein, DNA, lipids and other biomolecules. 
Levine et al. ${ }^{20}$ after modification by Rocha et al. ${ }^{7}$ Total nonheme iron was assayed spectrophotometrically as described by Bralet et al..$^{21}$

Liver glutathione (GSH) was analyzed by HPLC equipped with an electrochemical detector as described by Smith et al.,22 and glutathione peroxidase (GPX) was assayed spectrophotometrically with peroxide coupled to nicotinamide adenine dinucleotide phosphate (NADPH)/GPX reductase as reported by Wendel. ${ }^{23}$ Total superoxide dismutase (SOD) was assayed spectrophotometrically employing a non-enzymatic superoxide generator and nitroblue tetrazolium chloride as the radical detector. ${ }^{24}$ Protein concentrations in liver samples were determined by the Bradford's method. ${ }^{25}$

\section{Histochemical and immunohistochemical analysis}

Liver fragments were fixed in $3.7 \%$ buffered formalin or methacarn and processed for paraffin embedding prior to histochemical and immunohistochemical analysis.

Iron II/III histochemical detection was performed as described by Smith et al., ${ }^{26}$ whereas liver ferritin was localized by immunohistochemical reactivity, using chicken polyclonal anti-human ferritin antibody (Geneway, San Diego, USA) and rabbit polyclonal antibody against chicken immunoglobulin Y (IgY).

Liver protein carbonyls (DNP) were also immunolocalized as described by Astruc et al. ${ }^{27}$ Protein carbonyl groups were derivatized with 2,4-dinitrophenylhydrazine (DNP), while the DNP-conjugate forms were detected using an anti-DNP antibody. Polyclonal rabbit anti-DNP primary antibody (Sigma-Aldrich, St. Louis, MO, USA) and goat anti-rabbit peroxidase-conjugated secondary antibody (Upstate Cell Signaling Solutions, 7074, New York, USA) were used.

For the histological analyses, specimens were fixed in $2.5 \%$ glutaraldehyde, post-fixed with $1 \%$ osmium tetroxide for $1 \mathrm{~h}$, at $4{ }^{\circ} \mathrm{C}$, and embedded in Spurr resin (Spurr Embedding Kit, Ladd Research Industries, VT, USA). Ultrathin $60 \mathrm{~nm}$ sections were stained with $2 \%$ uranyl acetate and $0.5 \%$ lead citrate, both in PBS, and observed under a JEOL-100 CX transmission electron microscope (JEOL, Tokyo, Japan).

\section{Detection of TUNEL-positive cells}

Presence and localization of apoptotic cells within the liver were examined as described by Dekel et al.,$^{28}$ using an in situ Cell Death Detection Kit-alkaline phosphatase (Boehringer Mannheim, Roche, Germany). Analyses were performed under an Axioskop 2 microscope (Zeiss, Germany) using $100 \times$ objectives. Data were evaluated as total number of nicotinamide adenine dinucleotide phosphate (TUNEL)-positive cells per microscopic field $\left(\right.$ area $\left.=0.12 \mu \mathrm{m}^{2}\right)$ randomly selected from two distinct histological sections (from different liver fragments). A total of 50 microscopic fields were counted from each group. Data were expressed as the mean $( \pm \mathrm{SD}$, standard deviation) of TUNEL positive nuclei per $\mu \mathrm{m}^{2}$.

\section{Statistical analysis}

Parametric data were analyzed based on statistically significant differences by one-way analysis of variance (ANOVA); Tukey-Kramer and Kruskal-Wallis pos hoc tests were performed $(\mathrm{p}<0.05)$. As for the TUNEL-positive cell analyses, data were tested by the Student's $t$-test $(\mathrm{p}<0.05)$.

\section{Results}

Heme precursors and ALA-D activity

As expected, the levels of ALA significantly increased in the plasma $(\times 7-9)$, liver $(\times 6-24)$, and urine $(\times 12-13)$ of all SAME-treated groups when compared with the control group (Table 1). Higher ALA levels were found at higher doses of the ALA-D inhibitor, albeit not strictly in a SAME concentration-dependent manner. ALA levels in the urine samples collected between the $2^{\text {nd }}$ and $3^{\text {rd }}$ i.p. injection were significantly elevated in SAME-treated groups relative to the control $(\mathrm{p}<0.001)$ and in group IV relative to group II $(\mathrm{p}<0.05)$. Not surprisingly, both liver ALA-D activity (Table 2) and urinary COPRO concentrations (Table 3) reduced in SAME-treated animals. A significant increase in the clearance of ALA was found for group II versus control $(\mathrm{p}<0.05)$ and group III $(\mathrm{p}<0.001)$, and in group IV versus group III $(\mathrm{p}<0.01)$ (Table 3$)$.

\section{Putative indices of oxidative stress}

Protein carbonyl levels in rat tissues were widely distributed within each SAME-treated group; a significant augmented (2-fold) concentration of oxidized protein was found only in group II $(\mathrm{p}<0.001)$ (Table 4). Liver MDA was significantly higher in group III versus control only ( $\mathrm{p}<0.001)$. Unexpectedly, GSH, considered a reliable parameter to evaluate the cell redox balance, ${ }^{29}$ showed no differences among treated animals. The highly protective concentration of GSH in liver may explain this result. ${ }^{29}$

Liver total non-heme iron levels increased by ca. $50 \%$ upon $40 \mathrm{mg} \mathrm{SAME} \mathrm{kg}^{-1}$ body weight when compared to control and group II (Table 4). This supports the molecular link among SAME administration, ALA accumulation, iron 
Table 1. Mean plasma, liver and urine ALA levels for all the studied groups. The animals in group I were treated with saline solution $\left(0.67 \mathrm{~mL} \mathrm{~kg}^{-1}\right.$ body weight). Animals in groups II, III and IV were treated with 10, 40 and $80 \mathrm{mg} \mathrm{SAME} \mathrm{kg}^{-1}$ body weight, respectively. Data are shown as mean \pm SD (ranges)

\begin{tabular}{|c|c|c|c|c|}
\hline \multirow{2}{*}{ ALA levels (unit; n) } & \multicolumn{4}{|c|}{ Group (mg SAME kg-1 body weight) } \\
\hline & I (control) & II (10 mg) & III (40 mg) & IV (80 mg) \\
\hline $\operatorname{Plasma}^{\mathrm{a}}\left(\mu \mathrm{mol} \mathrm{L}{ }^{-1} ; \mathrm{n}=8\right)$ & $\begin{array}{l}0.48 \pm 0.04 \\
(0.45-0.60)\end{array}$ & $\begin{array}{c}3.30 \pm 0.80^{*} \\
(2.28-4.48)\end{array}$ & $\begin{array}{c}3.99 \pm 0.45^{*} \\
(3.26-4.56)\end{array}$ & $\begin{array}{l}4.39 \pm 0.93^{*}, * * \\
\quad(3.10-5.62)\end{array}$ \\
\hline $\begin{array}{l}\text { Liver }^{\mathrm{b}} \\
\left(\mathrm{nmol} \mathrm{L}^{-1} \text { per } \mathrm{mg} \text { protein; } \mathrm{n}=8\right)\end{array}$ & $\begin{array}{l}1.92 \pm 0.35 \\
(1.60-2.60)\end{array}$ & $\begin{array}{l}30.83 \pm 7.36^{*} \\
(22.13-39.99)\end{array}$ & $\begin{array}{c}42.73 \pm 4.38 * * \\
(40.40-49.77)\end{array}$ & $\begin{array}{c}45.80 \pm 11.74 * *, * * * \\
\quad(33.62-66.62)\end{array}$ \\
\hline $\begin{array}{l}\left.\text { Urine }^{\mathrm{c}} \text { (between the } 2^{\text {nd }} \text { and } 3^{\text {rd }} \text { i.p. }\right) \\
\left(\mu \mathrm{mol} \mathrm{L} \mathrm{L}^{-1} ; \mathrm{n}=8\right)\end{array}$ & $\begin{array}{l}4.15 \pm 1.69 \\
(1.66-7.66)\end{array}$ & $\begin{array}{c}49.93 \pm 5.3^{*} \\
(43.55-58.11)\end{array}$ & $\begin{array}{l}52.26 \pm 9.58^{*} \\
(39.13-66.67)\end{array}$ & $\begin{array}{c}54.26 \pm 8.44^{*}, * * \\
(40.51-67.63)\end{array}$ \\
\hline
\end{tabular}

aPlasma: ${ }^{*} \mathrm{p}<0.001$ is statistically different from control (group I), $* * \mathrm{p}<0.001$ is statistically different from group II (10 mg SAME kg ${ }^{-1}$ body weight). Multiple comparisons between the groups were made using the Tukey-Kramer test; ${ }^{b}$ liver: $* \mathrm{p}<0.05$ is statistically different from control (group I), $* * \mathrm{p}<0.001$ is statistically different from control (group I), ${ }^{* * *} \delta \mathrm{p}<0.05$ is statistically different from group II (10 mg SAME kg-1 body weight). Multiple comparisons between the groups were made using the Kruskal-Wallis test; ${ }^{c}$ urine: ${ }^{*} \mathrm{p}<0.001$ is statistically different from control (group I), ** $<<0.05$ is statistically different from group II (10 $\mathrm{mg} \mathrm{SAME} \mathrm{kg}^{-1}$ body weight). Multiple comparisons between the groups were made using the Kruskal-Wallis test.

Table 2. Liver ALA-D activity for animals in groups I, II, III and IV. Animals in group I were treated with saline solution $\left(0.67 \mathrm{~mL} \mathrm{~kg}^{-1}\right.$ body weight). Animals in groups II, III and IV were treated with 10, 40 and $80 \mathrm{mg} \mathrm{SAME} \mathrm{kg}^{-1}$ body weight, respectively $(\mathrm{n}=6)$

\begin{tabular}{lc}
\hline Group & \% ALA-D activity \\
\cline { 2 - 2 } I & Liver \\
II & 100 \\
III & $5.63 * * * * *$ \\
IV & $4.18^{* * * * * * *}$ \\
\hline
\end{tabular}

$* \mathrm{p}<0.05$ is statistically different from control (group I); $* * \mathrm{p}<0.01$ is statistically different from control (group I); $* * * p<0.001$ is statistically different from control (group I); ****p $<0.001$ is statistically different from group IV ( $80 \mathrm{mg}$ SAME $\mathrm{kg}^{-1}$ body weight). Multiple comparisons between the groups were made using the Kruskal-Wallis test.

deposition and oxidative imbalance. SAME administration strongly inhibits ALA-D, resulting in overproduced ALA. The follow up is ALA oxidation, which is known to be catalyzed by iron complexes, yielding oxygen reactive species. ${ }^{30,31}$ ALA also induces iron release from ferritin, ${ }^{30}$ providing iron to catalyze aerobic oxidation of various metabolites, including ALA itself, aminoacetone and triose phosphates. ${ }^{6}$ SA also inhibits heme synthesis, leading to nonheme iron accumulation in mitochondria and cytosol of normal reticulocytes. ${ }^{32}$ Liver total SOD activity and glutathione peroxidase (GPx) showed no differences (Table 4). As for SOD, this is consistent with previous study using acute SAME treatment. ${ }^{7}$ Concerning GPx, it is long known that the hepatic GSH highly buffers against oxidative insult by a high rate of GSH synthesis. ${ }^{8}$ This constitutes one of the protection mechanisms lost in a chronic liver imbalanced redox environment.

\section{Histochemical and immunohistochemical assays}

Liver iron accumulation was confirmed in all groups, although it was notably higher in group II (Figure 1E versus Figure 1A and 1I). In all groups, the distribution was more intense in the center of the classical hepatic lobule, surrounding the central vein.

DNP was evenly localized throughout the liver parenchyma in all the groups (Figures 1C, 1G, 1K),

Table 3. Mean \pm SD reduction in urinary COPRO for all treated groups. Mean \pm SD renal clearance of ALA for all the treated groups. Animals in group I were treated with saline solution $\left(0.67 \mathrm{~mL} \mathrm{~kg}^{-1}\right.$ body weight). Animals in groups II, III and IV were treated with 10,40 and $80 \mathrm{mg} \mathrm{SAME} \mathrm{kg}^{-1}$ body weight, respectively $(n=5)$

\begin{tabular}{|c|c|c|}
\hline Group & Reduction in urinary COPRO levels ${ }^{\mathrm{a}} / \%$ & Clearance of $\mathrm{ALA}^{\mathrm{b}}($ mean $\pm \mathrm{SD}) /\left(\mathrm{mL} \mathrm{min}{ }^{-1}\right)$ \\
\hline I & & $0.24 \pm 0.14$ \\
\hline II & 90 (ranging from 72 to 104 ) $*, * *, * * *$ & $0.39 \pm 0.18^{*, * *}$ \\
\hline III & 65 (ranging from 51 to 80 ) $* * *$ & $0.25 \pm 0.08$ \\
\hline IV & 79 (ranging from 50 to 118 )**** & $0.33 \pm 0.13 * * *$ \\
\hline
\end{tabular}

a Urinary COPRO: *data were normalized subtracting the values found for the control group; ${ }^{*} \mathrm{p}<0.001$ is statistically different from control (group I);

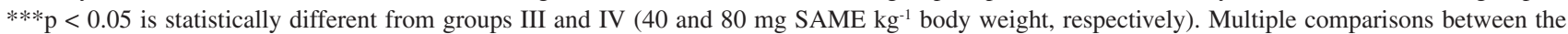
groups were made using the Tukey-Kramer test; ${ }^{b}$ clearance of ALA: $* \mathrm{p}<0.05$ is statistically different from control (group I); ** $<0.01$ is statistically different from group III (40 mg SAME kg ${ }^{-1}$ body weight); $* * * p<0.01$ is statistically different from group III (40 mg SAME kg-1 body weight). Multiple comparisons between the groups were made using the Kruskal Wallis test. 
Table 4. Mean liver protein carbonyl, lipid peroxidation, GSH, total non-heme iron content, SOD activity and GPx activity for all the studied groups. Animals in group I were treated with saline solution $\left(0.67 \mathrm{~mL} \mathrm{~kg}^{-1}\right.$ body weight). Animals in groups II, III and IV were treated with 10,40 and $80 \mathrm{mg} \mathrm{SAME} \mathrm{kg}^{-1}$ body weight, respectively. Data are shown as mean $\pm \mathrm{SD}$ (ranges)

\begin{tabular}{|c|c|c|c|c|}
\hline \multirow{3}{*}{$\begin{array}{l}\text { Biomarkers of oxidative } \\
\text { imbalance }\end{array}$} & \multicolumn{4}{|c|}{ Group (mg SAME $\mathrm{kg}^{-1}$ body weight) } \\
\hline & \multicolumn{4}{|c|}{ Liver } \\
\hline & I (control) & II $(10$ mg) & III (40 mg) & IV (80 mg) \\
\hline $\begin{array}{l}\text { Protein carbonyl }{ }^{\mathrm{a}} \\
\left(\mathrm{nmol} \mathrm{L} \mathrm{mg}^{-1} \text { protein; } \mathrm{n}=6\right)\end{array}$ & $6.04 \pm 2.10(3.75-9.20)$ & $13.78 \pm 3.99 *(10.13-20.76)$ & $5.34 \pm 1.18(4.11-7.50)$ & $4.99 \pm 0.68(3.99-6.10)$ \\
\hline $\begin{array}{l}\text { Lipid peroxidation }{ }^{\mathrm{b}}(\mathrm{MDA}) \\
\left(\mathrm{nmol} \mathrm{L} \mathrm{mg}^{-1} \text { protein; } \mathrm{n}=6\right)\end{array}$ & $2.63 \pm 0.40(2.22-3.17)$ & $2.92 \pm 0.60(2.11-3.67)$ & $3.41 \pm 0.42^{*, \#}(2.90-4.08)$ & $2.83 \pm 0.24(2.48-3.09)$ \\
\hline GSH $(n=5)$ & $0.22 \pm 0.04$ & $0.23 \pm 0.10$ & $0.23 \pm 0.05$ & $0.25 \pm 0.08$ \\
\hline $\begin{array}{l}\text { Total non-heme iron } \\
\left(\mu \mathrm{g} \mathrm{Fe} \mathrm{mg}^{-1} \text { tissue; } \mathrm{n}=8\right)\end{array}$ & $0.50 \pm 0.15$ & $0.48 \pm 0.10$ & $0.75 \pm 0.24 * *$ & $0.59 \pm 0.15$ \\
\hline SOD activity ( $\mathrm{U} \mathrm{mg}^{-1}$ protein) & $19.45 \pm 3.29$ & $20.86 \pm 4.16$ & $20.59 \pm 3.71$ & $23.26 \pm 3.88$ \\
\hline $\begin{array}{l}\text { GPx activity (nmol L-1 } \\
\text { NADPH } \text { min }^{-1} \mathrm{mg}^{-1} \text { protein) }\end{array}$ & $0.41 \pm 0.16$ & $0.52 \pm 0.22$ & $0.54 \pm 0.22$ & $0.45 \pm 0.15$ \\
\hline
\end{tabular}

${ }^{2}$ Liver protein carbonyl: *p $<0.001$ is statistically different from groups I (control), III and IV. Multiple comparisons between the groups were made using the Tukey-Kramer test; bliver MDA: * $p<0.001$ is statistically different from control (group I). ${ }^{\#} \mathrm{p}<0.05$ is statistically different from group IV (80 mg

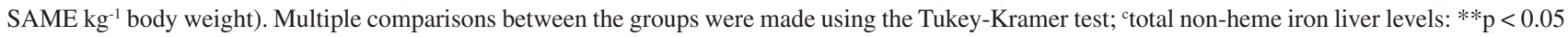
is statistically different from control (group I) and group II.

although the immunoreaction was also more intense in group II (Figure 1G).

The staining pattern of ferritin immunolocalization was weakly and uniformly distributed in the liver parenchyma in control (Figure 1B) and groups III and IV (Figure 1J), but particularly intense in $10 \mathrm{mg}$ SAME treated group (Figure 1F).

\section{Ultrastructural analysis}

As expected, the ultrastructural analysis showed preservation of the liver architecture and distinctive features characteristic of hepatocytes in all the specimens. In the control group (Figure 2A), hepatocytes contained up to two nuclei. After SAME treatment, the most remarkable findings under electron microscopic examination showed changes in the mitochondrial compartment. In groups II and IV (Figures 2B-D and 2I-J, respectively), the hepatic ultrastructure showed characteristics similar to those of the control group, except for part of the mitochondria, which were unusually small, oval or quasi-oval in shape, with increased mitochondrial matrix electron-density (Figures 2C and 2J). After the $40 \mathrm{mg}$ SAME $\mathrm{kg}^{-1}$ treatment (Figures 2E-H), hepatocytic mitochondria exhibiting higher mitochondrial matrix electron-density, suggestive of electron-dense inclusions, predominated over morphologically normal mitochondria. Mitochondria with electron lucent matrix but with atypical loss of cristae were also observed (Figure 2G). The specimens of groups II and III also displayed occasional discrete augmentation of lipid inclusions (Figure 2F) and heterophagosome-like organelles
(Figure 2D), myelin figures and atypical dilatations and vacuolization in the endoplasmic reticulum cisternae (Figure 2G). Nuclear organelles and nuclear membrane have maintained their structure in the experimental groups. All the specimens showed euchromatic nuclei with a prominent nucleolus.

\section{Presence of apoptotic cells}

Chromatin condensation and fragmentation were frequently visualized throughout the parenchyma in the liver of SAME-treated animals, and TUNEL assay confirmed that this finding was associated with programmed cell death. TUNEL stained nuclei in general were more numerous surrounding the central vein at the center of the classical lobule and progressively diminishing towards the periphery (Figures 3A-B).

SAME-treatment (Figure 3C) at the dose of $40 \mathrm{mg} \mathrm{kg}^{-1}$ increased the number of TUNEL positive nuclei by approximately 5 times when compared with control samples $(55.6 \pm 4.2 v s .10 .1 \pm 0.7, p=0.004)$, whereas the increase seen with $80 \mathrm{mg} \mathrm{kg}^{-1}$ was much more discrete $(14.4 \pm 0.8 \mathrm{vs}$. $10.1 \pm 0.7,1.4$-fold, $\mathrm{p}=0.012$ ). The $10 \mathrm{mg}$-SAME treatment did not significantly change the number of apoptotic cells (14.6 \pm 1.9 vs. $10.1 \pm 0.7, \mathrm{p}=0.087$ ).

\section{Discussion}

Direct administration of SAME to rats at $18 \mathrm{~h}$ intervals resulted in higher amounts of ALA in plasma, liver and urine when compared to control (Table 1). Another 

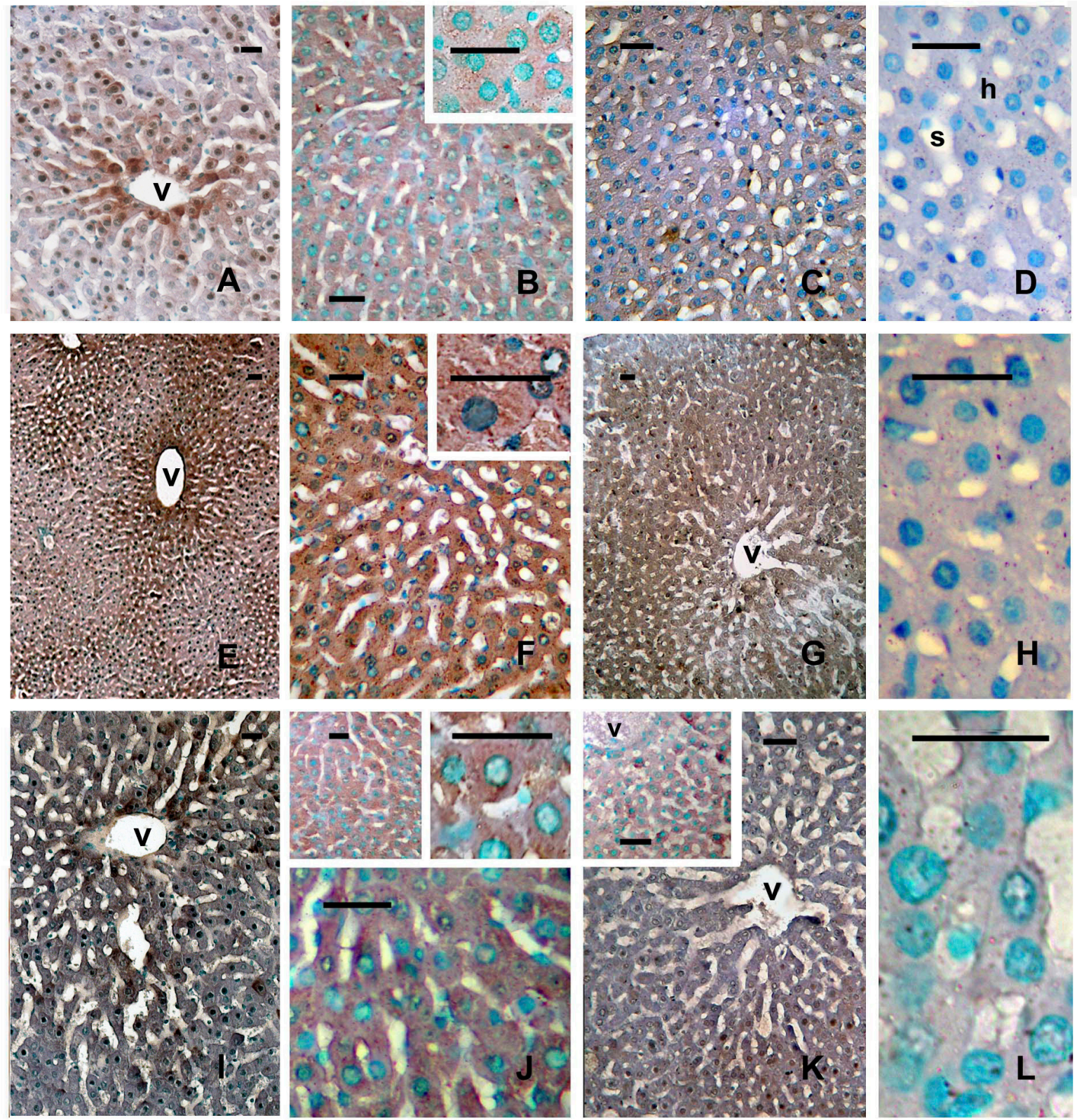

Figure 1. Localization of iron (A, E, I), ferritin (B, F, J) and DNP (C, G, K) in the liver of control (A-D) or SAME treated rats (10 mg, E-H; $40 \mathrm{mg}$ I-L; $80 \mathrm{mg}$, insert of Figures I-K). Stainable iron is observed as irregular dark granules in liver cell cytoplasm (arrows). The density of granules in the liver parenchyma varied with the animals' treatment (A, E, I and insert). By contrast, DNP immunoreactivity shows differences (C, G, K and insert) in intensity, but is uniformly distributed in liver cells. In general, immunoreaction for ferritin is weak in liver cells except in $10 \mathrm{mg}$ SAME-treated samples (B, F, J). v: portal vein; s: sinusoid; h: hepatocyte columns; p: portal area. Figures D, H and L are representative of the immunoreaction controls in which the primary antibody was replaced by non-immune rabbit serum, respectively, for anti-ferritin in the control group, anti-DNP in the $10 \mathrm{mg}$ SAME treated group, and anti-DNP reaction in the $40 \mathrm{mg}$ SAME treated group. The liver sections were counterstained with Mayer hematoxylin or methyl green solution.

consequence of ALA-D inhibition by SAME-generated SA catalyzed by esterases, confirmed by the data given in Table 2, is the downstream depression of urinary COPRO (Table 3). The fact that the values of the renal clearance of ALA by treated animals were similar to that of the control group (Table 3), but for group II, indicates that the increased levels of plasma ALA did not suffice to effectively alter the renal function. Blood accumulation and urinary excretion of ALA at concentrations above the normal levels have long been reported in symptomatic AIP carriers ${ }^{1,9,10}$ and have been associated with neurological manifestations and hepatoma incidence in AIP patients. ${ }^{6}$

Altogether, these data suggest that maximal effects of SA in rats can be reached at a dose ranging from 10 and $40 \mathrm{mg}$ SAME $\mathrm{kg}^{-1}$ body weight. It is possible that in the presence of high ALA levels, as that attained at SAME doses higher than 10-40 $\mathrm{mg} \mathrm{kg}^{-1}$ body weight, a competition between ALA and SA for the active site of ALA-D may 

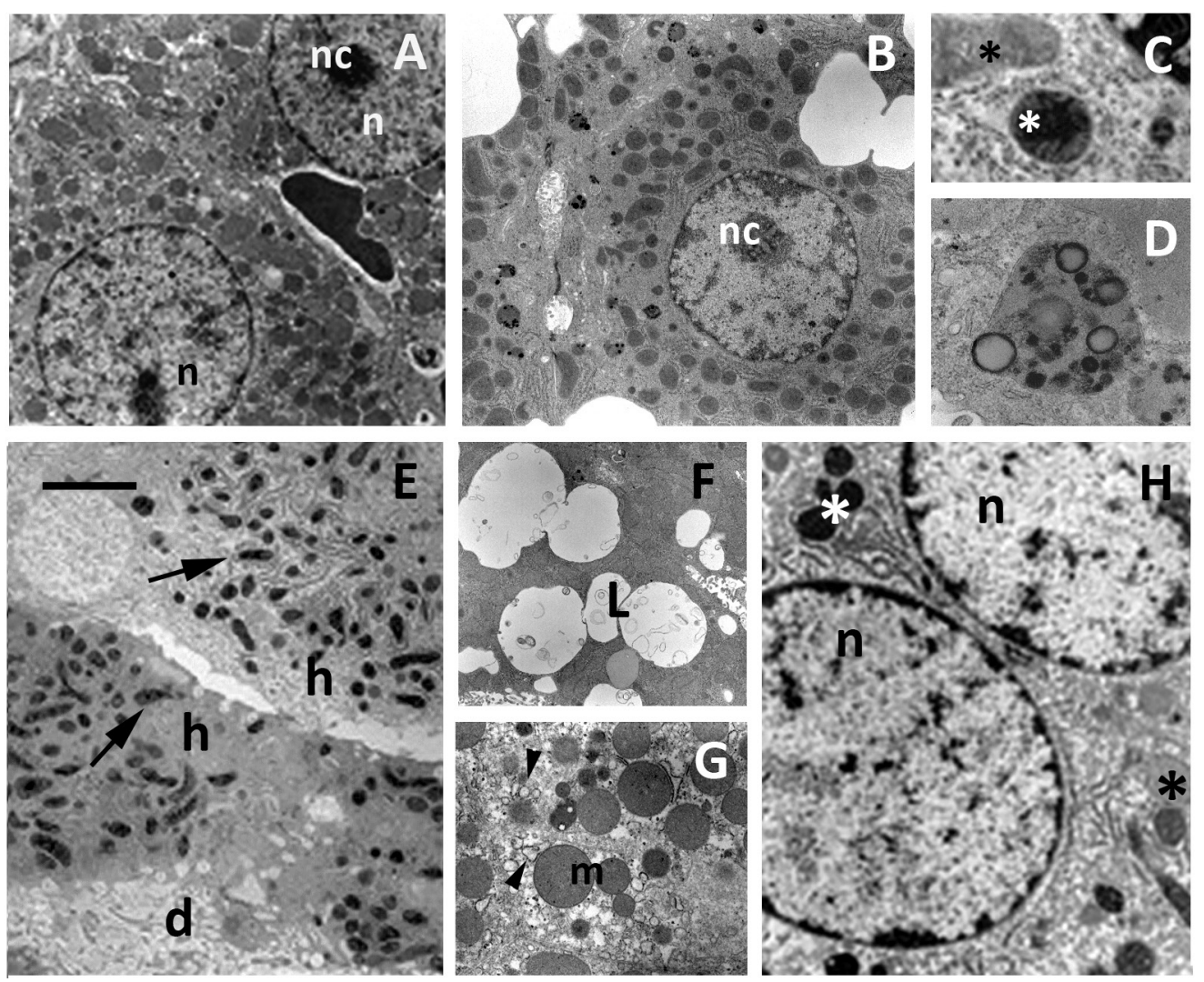

Figure 2. Electron microscopy analyses of the hepatic parenchyma: (A) control group; (B-D) $10 \mathrm{mg} \mathrm{SAME} \mathrm{kg}{ }^{-1}$; (E-H) $40 \mathrm{mg} \mathrm{SAME} \mathrm{kg}^{-1}$. Hepatocytes (h) show euchromatic nucleus (n), prominent nucleolus (nc) and cytoplasm rich in mitochondria. C and D, respectively, highlight mitochondria with electron dense matrix (white asterisk) and mitochondria with normal morphology (black asterisk), as well as a heterophagosome-like organelle, which are common ultrastructural findings in hepatocyte-treated animals. (E, H) Mitochondria with atypical electron dense matrix (white asterisk) and with electron dense inclusions (arrows) prevailed over mitochondria with normal appearance (black asterisk) in hepatocytes of $40 \mathrm{mg}$ SAME-treated animals. (F) Lipid droplets are particularly numerous in this group $(\mathrm{L})$ and occasionally also $(\mathrm{G})$ rounded mitochondria with scarce cristae $(\mathrm{m})$ surrounded by dilated endoplasmic reticulum cisternae (arrowheads). d: Space of Disse. Bar in E indicates $7 \mu \mathrm{m}$ (A, B, F), $2 \mu \mathrm{m}(\mathrm{C}, \mathrm{G}), 0.25 \mu \mathrm{m}$ (D), $20 \mu \mathrm{m}$ (E), or $5 \mu \mathrm{m}$ (H). The liver sections were stained with $2 \%$ uranyl acetate and $0.5 \%$ lead citrate.

happen, minimizing the inhibitory effects of SA over ALA-D and consequently the redox imbalance to the tissues. ${ }^{33,34}$ Data from tissue labeling assays offer additional support for this explanation, since the $10 \mathrm{mg}$ SAME-treated group was the most affected (Figure 1).

It is tempting to interpret the higher renal clearance of ALA observed in groups II and IV relative to group III to a faster removal of this metabolite from the body, preventing its accumulation and oxidative consequences in this organ.

The dose-effect response found for urinary ALA excretion reinforces this hypothesis (Table 1). In cells, only low quantities of ALA coexist with the heme precursors in the normal flow of heme biosynthesis. ${ }^{35}$ Thus, any excess of ALA produced by endogenous or exogenous factors is exported. ${ }^{35} \mathrm{~A}$ cellular mechanism to avoid intracellular accumulation of ALA must operate: possibly a detoxification mechanism occurs against the pro-oxidant properties of ALA. ${ }^{36}$ Although significant alterations in GSH content and SOD and GPx activities were not observed in the current study (Table 4), our results substantiate an acute effect of SAME-induced ALA accumulation of protein carbonyls, MDA and total non-heme iron levels. In addition to be well protected against oxidative injury by a high content of GSH, the liver may switch on adaptive responses in the early stages of toxicant challenge, thereby pre-conditioning the animal to further oxidative organ insult.

The treatment of rats with SAME resulted in a statistically significant dose-dependent increase of protein carbonyls in group II relative to control (Table 4). This finding was also confirmed by immunohistochemistry (Figures 1C, 1G, 1K). A dose-dependent decrease of protein carbonyl was observed in groups III and IV. Thus, maximal pro-oxidant effects of SA in rats can be triggered by a limiting dose of SAME in the range of 10-40 $\mathrm{mg} \mathrm{SAME} \mathrm{kg}^{-1}$ body weight. The oxidative damage can be partially suppressed in subsequent hours in response to an adapting stimulus. ${ }^{36}$ Significantly higher lipid peroxidation was observed in the liver only upon treatment with $40 \mathrm{mg} \mathrm{SAME} \mathrm{kg}^{-1}$ (Table 4). 

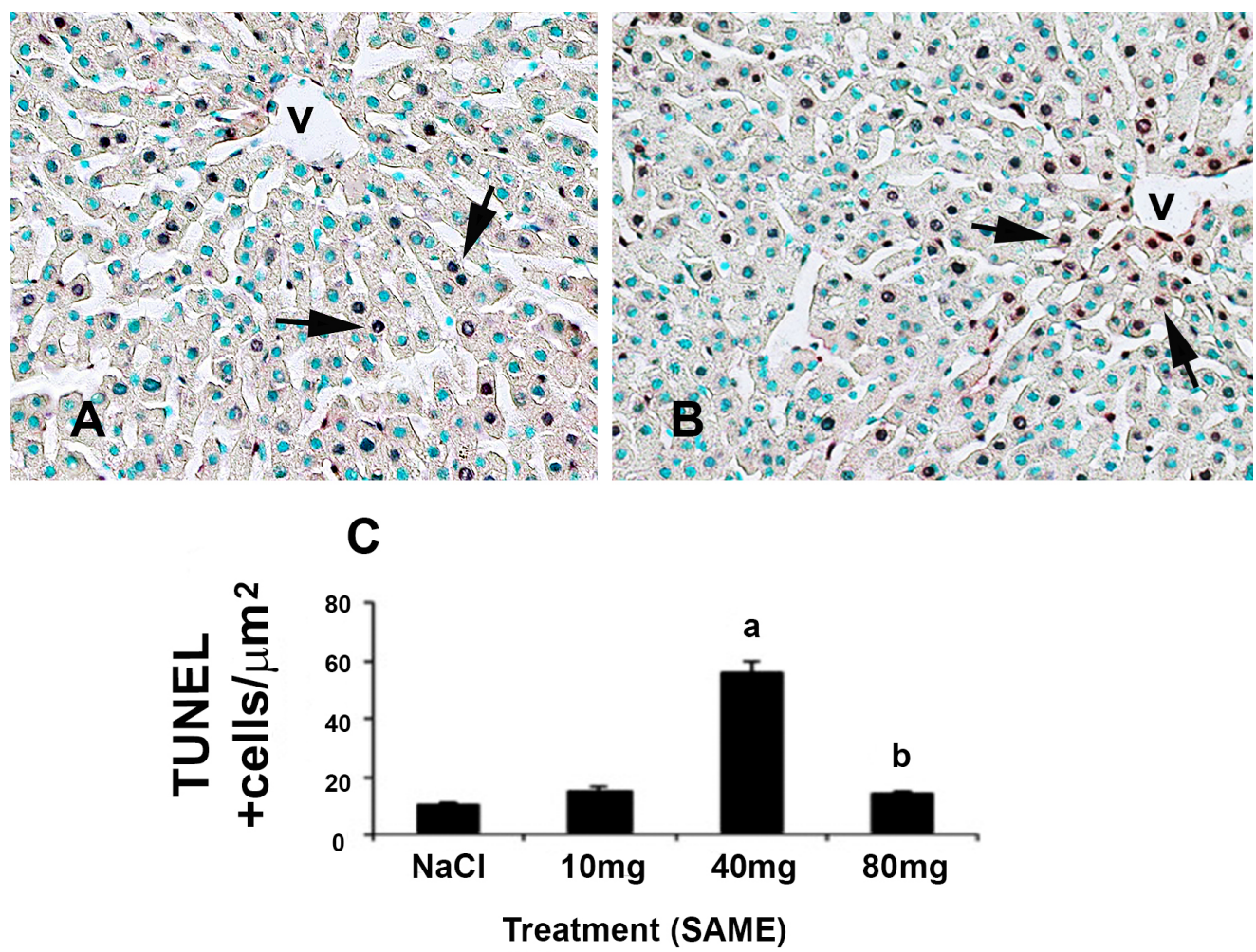

Figure 3. Representative photomicrographs of apoptotic cells labeled by TUNEL staining in liver of animals treated with $\mathrm{NaCl}$ (A) or SAME $40 \mathrm{mg}$ (B). Apoptotic cells were visualized with alkaline phosphatase-fast red and seen as reddish nuclear staining mainly in hepatocytes cells (arrows). In SAME-treated photomicrograph note that stained cells are mainly surrounding a center-lobular hepatic venule (v). Sections were counterstained with methyl green solution ( $0.5 \%$ in $0.1 \mathrm{M}$ sodium acetate buffer). Bar $=25 \mu \mathrm{m}$ for both photomicrographs. (C) Exposure to SAME 40 and $80 \mathrm{mg}(\mathrm{a}, \mathrm{p}<0.005 ; \mathrm{b}, \mathrm{p}<0.05)$ significantly increased the number of TUNEL positive cells in the hepatic tissue in comparison with control group $(\mathrm{NaCl})(\mathrm{n}=50 \mathrm{microscopic}$ fields from each group). Data were evaluated as total number of TUNEL-positive cells per microscopic field $\left(\operatorname{area}=0.12 \mu \mathrm{m}^{2}\right.$ ) randomly selected from two distinct histological sections (from different liver fragments). A total of 50 microscopic fields were counted from each group. Data were expressed as the mean $\left( \pm\right.$ S.D.) of TUNEL positive nuclei per $\mu \mathrm{m}^{2}$. Bars are S.D. The liver sections were counterstained with methyl green solution.

The hepatic ultrastructure changes found in SAME-treated rats occurred primarily in the mitochondrial compartment. Hepatocyte mitochondrial abnormalities after 10 and $40 \mathrm{mg} \mathrm{SAME} \mathrm{kg}^{-1}$ body weight treatment included bizarre shapes, extreme condensation of matrix, electron dense inclusions, swelling and atypical loss of cristae, also associated with hepatocyte dysfunction and damage in several other conditions such as human porphyria, experimental porphyria and in the use of porphyrogenic agents. ${ }^{37-39}$ Among these alterations, however, mitochondrial inclusions and increase of matrix electron density, indicative of mitochondrial damage, prevailed over others. Similar damage has been reported in several hepatic diseases, including human acute intermittent porphyria, ${ }^{33}$ although not in all cases,${ }^{15}$ as well as in rat hepatocytes intoxicated with carbon tetrachloride. Abnormal mitochondrial shapes and increased number of mitochondrial ghosts are also common morphological alterations related with human porphyria, also found in hepatocyte cultures exposed to porphyrogenic agents. ${ }^{37-39}$ The morphological effects of SAME in the mitochondria may be caused by the oxidative imbalance correlated here with hepatic lipid peroxidation and ALA accumulation. Accordingly, previous studies of swimming-trained ALA-treated rats ( $40 \mathrm{mg} \mathrm{kg}^{-1}$ body weight) revealed they underwent a shift from aerobic to glycolytic metabolism, which was attested by higher mobilization of muscle and liver glycogen, decreased activities of mitochondrial MnSOD, and elevated circulation of free fatty acids and lactic acid. ${ }^{40}$

The increase in apoptosis followed by $40 \mathrm{mg} \mathrm{kg}^{-1}$ SAME treatment is also in agreement with our findings. Intriguingly, apoptosis triggered by SAME seemed not to occur at doses higher than $40 \mathrm{mg} \mathrm{kg}^{-1}$. We propose that a self-limiting pro-oxidant rate for SA effects may operate in this model where antioxidant and pro-oxidant mechanisms are counterbalanced. Alternatively, our inability to determine apoptosis within the liver at minimal and maximal doses of SAME treatment may infer a timedependent process for which apoptotic figures become experimentally more evident in our assays.

Additionally, in the present study, (i) the morphology and number of autophagic vacuoles in experimental specimens were similar, (ii) myelin figures were similar 
in control and experimental specimens, (iii) lipid droplets seemed to be discretely augmented, and $(i v)$ no iron-positive granules related with mitochondrial damage were found.

Surprisingly, the group administered with the higher SAME dose $\left(80 \mathrm{mg} \mathrm{kg}^{-1}\right)$ did not show a dose-dependent effect for the redox parameters evaluated. An integrated and complex mechanism must be implicated therein. First, part of ALA accumulated in group IV must have been converted to 4,5-dioxovaleric acid (DOVA), a metabolite yielded through the aerobic oxidation of ALA. ${ }^{6}$ The similar profile of plasma and liver ALA levels and the data for the urinary ALA excretion also support this hypothesis (Table 1). Considering the differences in plasma ALA levels between groups II and IV, and proportional displacement of excess ALA to the extracellular medium, ${ }^{35}$ much more ALA should have been excreted in urine of group IV. Thus, it is possible that the lack of ALA-dose response was compensated by the production of DOVA. Despite DOVA, a highly electrophilic adductant to proteins, reportedly causes biological damage, it is expected to be less specific than ALA on cellular oxidative impairment, or takes longer to trigger its oxidative effects. Second, the renal clearance of ALA was higher for groups II and IV when compared to group III (Table 3). It seems likely that as higher the renal clearance for ALA, faster is the removal of this metabolite from the body, avoiding its accumulation and consequent oxidative effects. This may have prevented the establishment of a dose-dependent effect for group IV. This may also explain why some results showed that $40 \mathrm{mg}$ SAME led to significant different responses as compared to the control, whereas $10 \mathrm{mg}$ SAME was more effective. Again, the dose-effect dependence found for the urinary ALA excretion also supports this suggestion (Table 1) once only low quantities of ALA accumulates in cells. ${ }^{35}$ These data suggest the existence of a cellular mechanism able to avoid the intracellular accumulation of ALA, possibly a detoxification mechanism against the prooxidant properties of ALA. According to Demasi et al., ${ }^{36}$ liver, brain and soleus tissues are partially able to suppress the oxidative damage promoted by ALA in a longer term in response to an adaptive stimulus. Third, as for the biomarkers of oxidative stress determined in this study, the lack of a statistic difference for the treated groups versus the control might reflect effects of the nutritional stress. In this sense, fasting condition may have normalized the performance of treated and control groups. Fasting conditions reportedly favor mitochondrial damage as a consequence of a reduction in the amount of liver antioxidants, which would sensitize mitochondrion to the harmful action of reactive oxygen species (ROS). ${ }^{41}$ Vendemiale et al. ${ }^{42}$ showed that mitochondria isolated from fasting normal liver presented higher levels of oxidized lipids and lower amounts of ATP synthase in relation to the fed group. Interestingly, in conditions of feeding, the model study for porphyria based on the administration of SAME is ineffective. ${ }^{7}$ However, despite discrete, the increases in biomarkers for oxidative stress showed in this study are in agreement with the reported oxidative damage to biomolecules, organelles, and tissues promoted by ALA accumulation (Scheme 2).

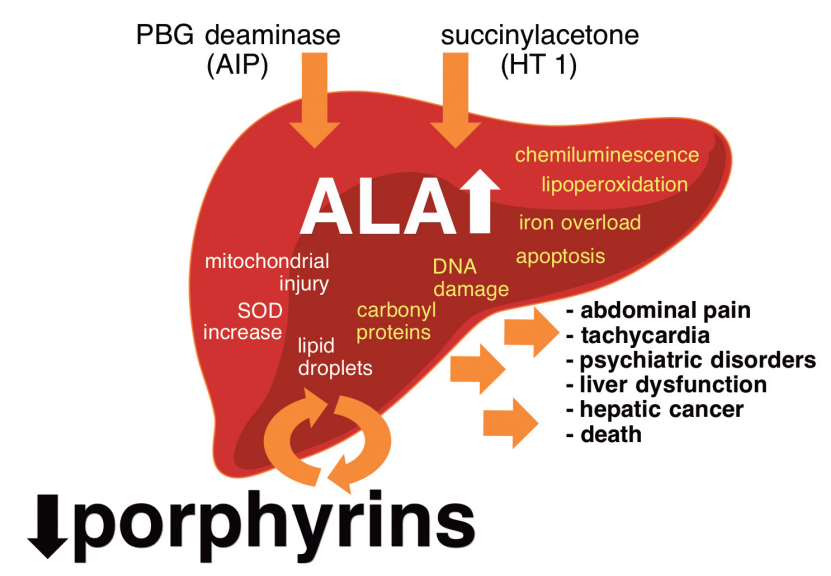

Scheme 2. Free radical hypothesis of inherited hepatic porphyrias related to the accumulation of ALA, the first precursor of the heme biosynthetic pathway. ALA is reportedly overproduced in the liver of AIP patients due to PBG deaminase deficiency and in HT1, owing to excess SA, a tyrosine catabolite that acts as a strong inhibitor of ALA dehydratase. Model studies with rat-administered SAME or $\mathrm{ALA}^{6}$ have revealed: (i) increased plasma ALA and urinary ALA clearance, accompanied by decreased urinary COPRO (references 4,43 and this work); (ii) liposome and membrane lipoperoxidation (reference 30 and this work); mitochondrial permeabilization and impaired functions (reference 7 and this work); elevated carbonyl proteins (this work); increased liver chemiluminescence; ${ }^{36}$ DNA strand breaks, 2'-deoxyguanosine (dGuo) oxidation and DOVA adduction; ${ }^{44-46}$ and apoptosis (this work). In vivo or post-mortem studies of AIP patients have shown increased SOD activities; ${ }^{40,45}$ ALA overload and porphyrin diminution ${ }^{4}$ plus deformed mitochondria, elevated iron deposits and lipid droplets. ${ }^{15} \mathrm{~A}$ bulk of data advocate the implication of these ALA-triggered biochemical changes in the hemodynamic, hepatic, social behavior and psychiatric manifestations of AIP and HT1. ${ }^{4}$ Accordingly, we have also reported oxidative damage to $\gamma$-aminobutyric acid (GABA) receptors in cerebral structures of ratchronically exposed to ALA or SAME. ${ }^{47-49}$

\section{Conclusions}

In conclusion, SA accumulation observed in hepatic tyrosinemia drives liver damage by overproduced ALA, mimicking the 'porphyric condition'. This system allows us to propose advances in the clinical management of individuals (mostly children) in early stages of the disease conditions. Valuable observations come out of assessable clinical parameters and diagnostic tools for determination of risk variables during the disease progression such as increased ALA in plasma and urine, as well as elevation of urinary COPRO because of ALA-D inhibition by SA. 
Although discrete, the increases observed in the biomarkers of oxidative imbalance (protein carbonyl, MDA, iron and ferritin) become possible assessments in clinical care for diagnoses and chronic intervention paradigms as they are consistent with oxidative damage promoted by ALA accumulation in humans and experimental animals reported elsewhere. ${ }^{6}$ Notwithstanding, the experimental model has limitations in human medical settings. Future clinical work may use approaches based on these aforementioned parameters to ameliorate the rare, but devastating health conditions in infancy and youth found in metabolic heme disorders.

The Scheme 2 summarizes in vitro and in vivo biochemical, hepatocytes and pathophysiological changes reported in this work and in the literature that hypothetically link ALA accumulation in both AIP and HT1 syndromes.

\section{Acknowledgments}

This work is dedicated in memoriam to Ângelo da Cunha Pinto, an outstanding Brazilian chemist devoted to the study of natural products and tireless member of the Brazilian Chemical Society. We thank the Brazilian agencies Fundação de Amparo à Pesquisa do Estado de São Paulo (FAPESP, Proc. 2006/056530-4), the Conselho Nacional de Desenvolvimento Científico e Tecnológico (CNPq, Proc. 300777/2005-1) and the FAPESP/INCT Redoxoma (Proc. 573530/2008-4) for the financial support of this work. We are indebted to Donna Porter (Dartmouth Medical School, NH) for kindly reviewing the manuscript, and to Cassius Vinicius Stevani for kindly performing the design of the Graphic Abstract.

\section{References}

1. Dehghani, S. M.; Haghighat, M.; Imanieh, M. H.; Karamnejad, H.; Malekpour, A.; Int. J. Prev. Med. 2013, 4, 1380.

2. Scott, C. R.; Am. J. Med. Genet., Part C 2006, 142C, 121.

3. Russo, P. A.; Mitchell, G. A.; Tanguay, R. M.; Pediatr. Dev. Pathol. 2001, 4, 212.

4. Sassa, S.; Br. J. Haematol. 2006, 135, 281.

5. Wyss, P. A.; Boynton, S.; Chu, J.; Roth, K. S.; Biochim. Biophys. Acta 1993, 1182, 323.

6. Bechara, E. J.; Dutra, F.; Cardoso, V. E.; Sartori, A.; Olympio, K. P.; Penatti, C. A.; Adhikari, A.; Assunção, N. A.; Comp. Biochem. Physiol., Part C: Toxicol. Pharmacol. 2007, 146, 88 and references therein.

7. Rocha, M. E. M.; Bandy, B.; Costa, C. A.; Barros, M. P.; Pinto, A. M. P.; Bechara, E. J. H.; Free Radical Res. 2000, 32, 343.

8. Pantopoulos, K.; Schipper, H.; Principles of Free Radical Biomedicine, $1^{\text {st }}$ ed.; Nova Biomedical Books: New York, 2012.
9. Floderus, Y.; Sardh, E.; Möller, C.; Andersson, C.; Rejkjaer, L.; Andersson, D.; Harper, P.; Clin. Chem. 2006, 52, 701.

10. Cappellini, M. D.; Brancaleoni, V.; Graziadei, G.; Tavazzi, D.; Di Pierro, E.; Intern. Emerg. Med. 2010, 5, S73.

11. Kang, D.; Hamasaki, N.; Curr. Med. Chem. 2005, 12, 429.

12. Peng, Q.; Berg, K.; Moan, J.; Kongshaug, M.; Nesland, J. M.; Photochem. Photobiol. 1997, 65, 235.

13. Morliere, P.; Hug, G. L.; Patterson, L. K.; Maziere, I. C.; Ausseil, J.; Dupas, J. L.; Ducroix, J. P.; Santus, R.; Filipe, P.; Biochim. Biophys. Acta 2014, 1840, 3190.

14. Laafi, J.; Homedan, C.; Jacques, C.; Gueguen, N.; Schmitt, C.; Puy, H.; Reynier, P.; Carmen Martinez, M.; Malthièry, Y.; Biochimie 2014, 106, 157.

15. Biempica, L.; Kosower, N.; Ma, M. H.; Goldfisher, S.; Arch. Pathol. 1974, 98, 336.

16. Murata, K.; Sakai, T.; Morita, Y.; Iwata, T.; Dakeishi, M.; J. Occup. Health 2003, 45, 209.

17. Sassa, S.; Enzyme 1982, 28, 133.

18. Cypriani, M. G. S. C.; Alves, A. N. L.; Bechara, E. J. H.; Assunção, N. A.; J. Braz. Chem. Soc. 2014, 25, 1918.

19. Esterbauer, H.; Lang, J.; Zadravec, S.; Slater, T. F.; Methods Enzymol. 1984, 105, 319.

20. Levine, R. L.; Garland, D.; Oliver, C. N.; Amici, A.; Climent, I.; Lenz, A. G.; Ahn, B. W.; Shaltiel, S.; Stadtman, E. R.; Methods Enzymol. 1990, 186, 464.

21. Bralet, J.; Schreiber, L.; Bouvier, C.; Biochem. Pharmacol. 1992, 43, 979.

22. Smith, N. C.; Dunnett, M.; Mills, P. C.; J. Chromatogr. B: Biomed. Sci. Appl. 1995, 673, 35.

23. Wendel, A.; Methods Enzymol. 1981, 77, 325.

24. Rao, U. M.; Free Radical Biol. Med. 1989, 7, 513.

25. Bradford, M. M.; Anal. Biochem. 1976, 72, 248.

26. Smith, M. A.; Harris, P. L.; Sayre, L. M.; Perry, G.; Proc. Natl. Acad. Sci. U.S.A. 1997, 94, 9866.

27. Astruc, T.; Marinova, P.; Labas, R.; Gatellier, P.; SantéLhoutellier, V.; J. Agric. Food Chem. 2007, 55, 9554.

28. Dekel, R.; Zvibel, I.; Brill, S.; Brazovsky, E.; Halpern, Z.; Oren, R.; Dig. Dis. Sci. 2003, 48, 1642.

29. Kalinina, E. V.; Chernov, N. N.; Novichkova, M. D.; Biochemistry (Moscow) 2014, 79, 1562.

30. Oteiza, P. I.; Kleinman, C. G.; Demasi, M.; Bechara, E. J.; Arch. Biochem. Biophys. 1995, 316, 607.

31. Monteiro, H. P.; Abdalla, D. S.; Augusto, O.; Bechara, E. J.; Arch. Biochem. Biophys. 1989, 271, 206.

32. Garrick, L. M.; Gniecko, K.; Liu, Y.; Cohan, D. S.; Grasso, J. A.; Blood 1993, 81, 3414.

33. Tschudy, D. P.; Hess, R. A.; Frykholm, B. C.; J. Biol. Chem. 1981, 256, 9915.

34. Venkateswar, V.; Padmanaban, G.; Arch. Biochem. Biophys. 1991, 290, 167.

35. Sinclair, P.; Granick, S.; Anal. Biochem. 1977, 79, 380. 
36. Demasi, M.; Costa, C. A.; Pascual, C.; Llesuy, S.; Bechara, E. J.; Free Radical Res. 1997, 26, 235.

37. Granick, S.; J. Biol. Chem. 1963, 238, 2247.

38. Reynolds, E. S.; J. Cell Biol. 1965, 25, 53.

39. Biempica, L.; Kosower, N. S.; Roheim, P. S.; Lab. Invest. 1971, 24, 110.

40. Pereira, B.; Curi, R.; Kokubun, E.; Bechara, E. J.; J. Appl. Physiol. 1992, 72, 226.

41. Skulachev, V. P.; FEBS Lett. 1998, 423, 275.

42. Vendemiale, G.; Grattagliano, I.; Caraceni, P.; Caraccio, G.; Domenicali, M.; Dall'Agata, M.; Trevisani, F.; Guerrieri, F.; Bernardi, M.; Altomare, E.; Hepatology 2001, 33, 808.

43. Karim, Z.; Lyoumi, S.; Nicolas, G.; Deybach, J. C.; Gouya, L.; Puy, H.; Clin. Res. Hepatol. Gastroenterol. 2015, 39, 412.
44. Onuki, J.; Medeiros, M. H. G.; Bechara, E. J. H.; Di Mascio, P.; Biochim. Biophys. Acta 1994, 1225, 259.

45. Fraga, C.; Onuki, J.; Lucesoli, F.; Bechara, E. J. H.; Di Mascio, P.; Carcinogenesis 1994, 15, 2241.

46. Douki, T.; Onuki, J.; Medeiros, M. H. G.; Bechara, E. J. H.; Cadet, J.; Di Mascio, P.; Chem. Res. Toxicol. 1998, 11, 150.

47. Medeiros, M. H. G.; Marchiori, P. E.; Bechara, E. J. H.; Clin. Chem. 1982, 28, 242.

48. Demasi, M.; Penatti, C. A. A.; DeLucia, R.; Bechara, E. J. H.; Free Radical Biol. Med. 1996, 20, 291.

49. Adhikari, A.; Penatti, C. A. A.; Resende, R. R.; Ulrich, H.; Britto, L. R. G.; Bechara, E. J. H.; Brain Res. 2006, 1093, 95.

Submitted: September 23, 2016 Published online: November 8, 2016 